change from baseline of the modified Sharp scores and proportion of patients in whom joint destruction was arrested after 24 weeks of treatment.

\begin{tabular}{lllll}
\multicolumn{4}{l}{ Abstract FRI0061 Table 1} \\
\hline & Placebo & $\mathbf{3 0} \mathbf{~ m g}$ & $\mathbf{7 5} \mathbf{m g}$ & $150 \mathrm{mg}$ \\
\hline Mod. Sharp Score: mean & 4.33 & $2.36 \mathrm{p}=$ & $2.25 \mathrm{p}=$ & $1.72 \mathrm{p}=$ \\
change & & 0.005 & 0.003 & 0.0004 \\
Mod. Sharp Score:\% pt w/no & $16.7 \%$ & $31 \% \mathrm{p}=$ & $24 \% \mathrm{p}=$ & $31 \% \mathrm{p}=$ \\
change & & 0.026 & 0.234 & 0.022 \\
\hline
\end{tabular}

Conclusion In patients with erosive disease, the rate of deterioration was significantly less in those who received anakinra. Significantly more patients with erosive RA who received anakinra for 24 weeks demonstrated an arrest of progressive joint damage. Moreover, an increasing benefit was associated with increasing dosages.

\section{FRI0062 EFFECTS OF METHOTREXATE AND LONG TERM LOW PREDNISONE DOSES ON BONE MINERAL DENSITY IN PATIENTS WITH EARLY SEVERE RHEUMATOID ARTHRITIS}

Cl Chirieac, E Rezus, B Florica, D Stratan, R Chiriac. Rheumatology, Rehabilitation Hospital - University of Medicine and Pharmacy, lasi, Romania

\subsection{6/annrheumdis-2001.1191}

Background Patients suffering from rheumatoid arthritia (RA) may feature significant loss of bone mineral density (BMD). early aggressive treatment and sometimes low corticosteroids doses are required; however, long term effects on bone are not extensively characterised.

Objectives To assess the effects of $10 \mathrm{mg}$ prednisone daily +7.5 mg methotrexate (MTX) on BMD in patients with early active and severe RA.

Methods 32 patients with active RA, with a disease duration less than 2 years, without prior treatment with any disease modifying antirheumatic drugs were randomised to receive either MTX and prednisone or sulphasalazine alone. Osteoporosis treatment was not permitted. Disease activity and BMD were monitored at baseline, 6, 12 and 24 months; BMD was determined by quantitative ultrasound at the calcis bone and was appreciated as broadband ultrasound attenuation (BUA) and quantitative ultrasound index (QUI). BMD loss was calculated in \% of baseline. Subgroup analysis (high and low disease activity) was performed upon ESR and CRP values.

Results After 6 and 12 months of treatment mean\% BUA has decreased significantly $(p<0.05)$ compared to baseline in both study groups, but greater in patients with high disease activity; after 24 months BMD has fallen significantly more in the combination group in patients with severe RA (- 3.5\%) compared to monotherapy group in patients with mild disease $(+0.07 \%, \mathrm{p}<$ $0.05)$. Change in BMD correlates more closely with measure of inflammation than with administration of prednosone and MTX.

Conclusion High disease activity is closely associated with bone loss in early active severe RA compared to bone loss due to aggressive therapy including MTX and low doses prednisone.
FRI0063 ANAKINRA REDUCES THE RATE OF JOINT DESTRUCTION AFTER 1 YEAR OF TREATMENT IN A RANDOMISED CONTROLLED COHORT OF PATIENTS WITH RHEUMATOID ARTHRITIS

${ }^{1} \mathrm{~B}$ Bresnihan, ${ }^{2} \mathrm{RD}$ Newmark, ${ }^{2} \mathrm{~S}$ Robbins, ${ }^{2} \mathrm{D}$ McCabe, ${ }^{3} \mathrm{HK}$ Genant. ${ }^{1}$ Department of Rheumatology, St. Vincent's University Hospital, Dublin, Ireland; ${ }^{2}$ Clinical Development, Amgen Inc., Thousand Oaks, USA; ${ }^{3}$ Department of Radiology, University of San Francisco, San Francisco, USA

\subsection{6/annrheumdis-2001.1192}

\section{Background}

Objectives To assess the effect of ankinra on progressive joint damage in patients with rheumatoid arthritis after 12 months of treatment.

Methods 472 patients were randomised to a 24 week study. On completing the 24 week, placebo-controlled, randomised clinical trial, patients receiving anakinra 30,75 or $150 \mathrm{mg}$ daily continued blinded treatment for a further 24 weeks. Patients originally randomised to placebo were re-randomised to blinded treatment with one of the 3 anakinra doses for an additional 24 weeks resulting in a blinded cohort of patients $(\mathrm{N}=309)$ followed for up to 1 year by radiographic assessments, using a modified Sharp method (Genant A\&R, 41:1583, 98).

Results Treatment with 75 or $150 \mathrm{mg}$ anakinra was significantly superior in terms of reducing joint destruction after 1 year, when compared to the group of patients originally randomised to placebo. This analysis demonstrated a dose proportional relationship with increasing doses of anakinra providing superior reduction of joint destruction when measured by a modified Sharp score.

Abstract FRI0063 Table 1 p-values for pairwise comparisons vs placebo are the result of an analysis using a repeated measures mixed model.

\begin{tabular}{lllll}
\hline & $\begin{array}{l}\text { Placebo } \mathrm{n}= \\
59\end{array}$ & $\begin{array}{l}30 \mathrm{mg} \mathrm{n} \\
=66\end{array}$ & $\begin{array}{l}75 \mathrm{mg} \mathrm{n} \\
=64\end{array}$ & $\begin{array}{l}150 \mathrm{mg} \mathrm{n} \\
=48\end{array}$ \\
\hline $\begin{array}{l}\text { Mean change in mod. Sharp } \\
\text { score after 1 year }\end{array}$ & 3.81 & $\begin{array}{l}2.43 \mathrm{p}= \\
0.099\end{array}$ & $\begin{array}{l}1.91 \mathrm{p}= \\
0.025\end{array}$ & $\begin{array}{l}1.90 \mathrm{p}= \\
0.025\end{array}$ \\
\hline
\end{tabular}

Conclusion Anakinra provides a statistically significant reduction in joint destruction, compared with patients originally randomised to placebo after 1 year of treatment. The reduction in joint destruction was dose proportional.

\section{FRI0064 PENTOXIFYLLINE THERAPY FOR REMISSION MAINTENANCE IN RHEUMATOID VASCULITIS}

'LO Damian, 'S Rednic, ${ }^{2} \mathrm{~A}$ Cristea, ${ }^{1} \mathrm{H}$ Bolosiu. 'Rheumatology; ${ }^{2}$ Immunology, University of Medicine and Pharmacy Cluj-Napoca, Cluj-Napoca, Romania

\subsection{6/annrheumdis-2001.1193}

Background Pentoxifylline (PTX), a phosphodiesterase inhibitor, is a vasodilator and antiplatelet drug credited with TNF $\alpha$ transcription inhibition as well. PTX was successfully used in refractory cases of rheumatoid arthritis and in some vasculitides, mainly cutaneous.

Objectives The study aim was to evaluate the efficacy of PTX given as monotherapy after induction of remission in systemic rheumatoid vasculitis (RV). 